\title{
COMENTÁRIOS SOBRE OS CONCEITOS DE CARÁTER INTELIGÍVEL, CARÁTER EMPÍRICO E CARÁTER ADQUIRIDO EM SCHOPENHAUER
}

\author{
COMMENTS ON THE CONCEPTS OF INTELLIGIBLE \\ CHARACTER, EMPIRICAL CHARACTER AND CHARACTER \\ ACQUIRED IN SCHOPENHAUER
}

\author{
André Luiz Simões Pedreira*
}

Recebido: 05/2017

Aprovado: 10/2017

\begin{abstract}
Resumo: Nosso artigo pretendeu comentar a teoria dos caracteres de Schopenhauer, por meio de um estudo dos conceitos de caráter inteligível, caráter empírico e caráter adquirido, no intuito de compreender sua tese da imutabilidade do caráter com fins ao entendimento de que apesar de visões distintas acerca dos caracteres, Schopenhauer e Kant convergem com relação à solução do impasse da doutrina da coexistência da liberdade com a necessidade. Para a realização da proposta, utilizou-se da obra magna de Schopenhauer, a saber, O Mundo como Vontade e Representação (1819) que foi basilar na tessitura do texto que ora se apresentou, embora algumas passagens da primeira crítica de Kant e de alguns comentadores tornaram-se igualmente importantes para o desenvolvimento do percurso.

Palavras-Chave: Caráter; Liberdade; Necessidade.
\end{abstract}

\begin{abstract}
Our article intends to comment on Schopenhauer's theory of characters, through a study of the concepts of intelligible character, empirical character and acquired character, in order to understand his thesis of the immutability of the character with the purpose to the understanding that although different visions about the Characters, Schopenhauer and Kant converge in relation to the solution of the impasse of the doctrine of the coexistence of freedom with necessity. For the realization of the proposal, Schopenhauer's masterpiece, The World as Will and Representation (1819) was used, which was based on the text of the present text, although some passages of the first criticism of Kant and some Commentators have become equally important for the development of the course.
\end{abstract}

Key-words: Character; Freedom; Need.

\section{Introdução}

Nisto o homem não faz exceção ao restante da natureza: também ele tem uma natureza fixa, seu caráter imutável, que, todavia, é bem individual e, em cada um, é outro. Para nossa apreensão este é mesmo empírico, mas por isso mesmo apenas fenômeno. O que ele possa ser de acordo com a sua essência em si mesma chama-se caráter inteligível ${ }^{1}$

No prefácio à primeira edição do Mundo como Vontade e Representação, Schopenhauer recomendou, como exigência à leitura desta mesma obra, uma familiaridade com os escritos de Kant, que além de tornar claras algumas questões ali expostas, encarrega-se de mostrar a influência do kantismo na fundação do seu sistema. Assim, o filósofo externou sua admiração por Kant, quando disse:

\footnotetext{
* Mestre em Filosofia da Educação pela Faculdade de Educação da Universidade Federal da Bahia (UFBA/FACED). Professor Assistente de Epistemologia e de Filosofia da Universidade do Estado da Bahia (UNEB). Avenida Lindolfo Azevedo Brito, 1170 - Centro - CEP: 46100/000 - Brumado/BA. Telefone: 071.8822.4379. E-mail: andreluiz.pedreira@hotmail.com

Problemata: R. Intern. Fil. v. 8. n. 3 (2017), p. 143-159 ISSN 2236-8612

doi:http://dx.doi.org/10.7443/problemata.v8i3.34285
} 
Considero esta doutrina de Kant da coexistência da liberdade com a necessidade como a maior das realizações da profundeza humana. Ela e a estética transcendental são dois diamantes na coroa da fama kantiana que nunca esmaecerá. ${ }^{2}$

$\mathrm{Na}$ explicação sobre a doutrina da coexistência da liberdade com a necessidade, Kant se propôs a mostrar que em relação aos fenômenos, a causalidade encontra-se situada sob dois aspectos, sendo um inteligível quanto a sua ação, que seria o caráter da coisa em si mesma, sem qualquer referência a experiência, enquanto busca pela sua causa, e o outro sensível quanto aos seus efeitos, cuja causa necessariamente deve ser buscada no mundo da experiência, não havendo, segundo o Copérnico da teoria do conhecimento, nenhuma contradição nem conflito ao se encontrar a liberdade e a necessidade coexistindo em uma mesma ação, quando a comparamos com sua causa inteligível ou sensível. Diz Kant:

num sujeito do mundo dos sentidos, um caráter empírico mediante o qual as suas ações enquanto fenômenos, se interconectariam completamente com outros fenômenos segundo leis constantes da natureza e poderiam ser derivadas destes, enquanto eles são as suas condições, constituindo, pois, em conjunção com os mesmos, membros de uma única série da ordem natural. Em segundo lugar, ter-se-ia que lhe conceder ainda um caráter inteligível mediante o qual aquele sujeito é a causa daquela ação enquanto fenômeno, ele mesmo, no entanto, não se subordinando a quaisquer condições da sensibilidade e não sendo, pois, um fenômeno. Ao primeiro também se poderia chamar de caráter de uma tal coisa no fenômeno, e ao segundo de caráter da coisa em si mesma.

Conforme seu caráter empírico, as ações do homem "estariam submetidas à ligação causal segundo todas as leis da determinação," " que estabelece uma relação necessária entre as causas naturais. Por conseguinte, suas ações sofreriam influências do mundo externo e suas causas seriam explicáveis segundo leis naturais e conhecidas por recorrência à experiência, já que "tudo o que ocorre encontra suas causas nos fenômenos (do estado precedente)." ${ }^{5}$ Por outro lado, enquanto caráter inteligível, as ações do homem seriam livres, ou seja, não estariam presas à conexão com os fenômenos enquanto causas, nem estariam sujeitas às variações temporais, pois "na medida em que é noumenon, nele nada ocorre, não é encontrada qualquer mudança, que reclama uma determinação dinâmica de tempo" ${ }^{6}$ Sendo, pois, o homem compreendido duplamente: enquanto determinado por uma causa empírica, quando tomado como ser natural e enquanto determinado por uma causa inteligível, quando tomado como coisa em si.

Ao se apropriar da doutrina da coexistência da liberdade com a 
necessidade, Schopenhauer a subverteu em seu cerne, pois, diferente de Kant que atribuiu um fundamento racional para o caráter inteligível, o filósofo o estabeleceu com referência à Vontade, definindo-o como a própria Vontade livre. ${ }^{7}$ Assim, as ações segundo seu caráter inteligível não teriam nenhuma causa advinda do mundo fenomênico, pois o caráter inteligível é a própria vontade livre. Para Schopenhauer, a vontade ou o caráter inteligível não se encontra numa relação de causalidade, ou mesmo fundamento, com o caráter empírico, pois, esta é uma forma que não se aplica à vontade, que é grundlos, isto é, sem razão ou causa. A causalidade diz respeito à mudança, ou seja, aos fenômenos que estão vinculados necessariamente a uma relação ascendente de causa e efeito, que sempre pressupõe o tempo. A vontade ou o caráter inteligível, portanto, longe de toda causalidade, não admite mudança de estado e condição, pois que é imutável e incorrigível.

É preciso, no entanto, ter presente a diferença de concepção do caráter inteligível em Kant e em Schopenhauer. Na Crítica da Filosofia Kantiana, o filósofo conta entre o que há de mais excelente na filosofia de Kant a distinção entre caráter empírico e caráter inteligível. Mas recusa a dedução do caráter inteligível como fundamento do sensível através da categoria da causalidade além de todo fenômeno. ${ }^{8}$

O caráter empírico manifesta no tempo o caráter inteligível, porém, essa manifestação não deve ser concebida como relação causal. Assim sendo, manifestar o caráter inteligível não significa afirmar que ele tenha, nessa visibilidade no corpo, entrado nas formas princípio de razão, a saber, tempo, espaço e causalidade, que são as formas do fenômeno, "senão ele seria apenas visibilidade e não o que se torna visível." " A manifestação do caráter inteligível no caráter empírico encontra algumas dificuldades, pois que esse processo de espelhamento, em cada indivíduo, passa pelos ditames da cultura que, por sua vez, pode levá-lo a um conhecimento equivocado do seu próprio caráter e a sua consequente negação, ainda que verifique, a partir de si mesmo, a imutabilidade do seu caráter constatada pela observância de suas ações que vão se dando parcialmente ao longo dos anos. Esse equívoco acerca do próprio caráter leva o indivíduo a não se reconhecer pelo que constata quotidianamente, mas numa imagem completamente inversa - o que acarreta inúmeros sofrimentos.

Esse processo incorre num problema de falsa consciência, onde o indivíduo execra o que é, empenhando-se em tentativas nunca alcançadas de mudança de caráter. Tal pretensão surge, porque o indivíduo se imagina suficientemente livre em relação à possibilidade de mudança de caráter, porém, a experiência se encarrega de lhe mostrar a nulidade desses esforços, ainda que no silêncio de suas expressões. 
Daí advém o fato notável de que cada um se considera a priori a si mesmo como inteiramente livre, até mesmo em suas ações isoladas, e pensa que poderia a todo instante começar um outro decurso de vida, o que equivaleria a tornar-se outrem. No entanto, só a posteriori, por meio da experiência, percebe, para sua surpresa, que não é livre, mas está submetido à necessidade. Percebe que, apesar de todos os propósitos e reflexões, não muda sua conduta, e desde o início até o fim de sua vida tem de conduzir o mesmo caráter por ele próprio execrado e, por assim dizer, desempenhar até o fim o papel que lhe coube. ${ }^{10}$

Enquanto manifestação do caráter inteligível, o caráter empírico é fenomênico. E enquanto fenômeno, as ações dos indivíduos estão necessariamente vinculadas à dependência dos motivos, sejam estes reais ou ilusórios, que determinam seu aparecimento no tempo e no espaço, dentro das formas do entendimento humano em uníssono com as formas da cultura, mas o ato originário da ação mesma não se encontra nessas formas, já que é o caráter inteligível, onde se encontra, portanto, a liberdade do indivíduo e não em sua dimensão empírica, pois não há liberdade para aquilo que se encontra no mundo dos fenômenos, dado o determinismo ao qual está submetido.

Os motivos não determinam o caráter do homem, mas tão-somente o fenômeno desse caráter, logo as ações e atitudes, a feição exterior de seu decurso de vida, não sua significação íntima e conteúdo: estes últimos procedem do caráter, que é o fenômeno imediato da Vontade, portanto sem fundamento. ${ }^{11}$

Os motivos são a forma da causalidade no homem, que podem ser reais ou ilusórios. Além dos motivos sensíveis e/ou reais que determinam as ações necessariamente, assim também podem se tornar igualmente necessários os motivos ilusórios e/ou abstratos ao mobilizarem as ações virulentamente, graças à emergência da racionalidade nos indivíduos. A racionalidade permitiu o ultrapassamento das determinações do presente intuitivo ao estado de abstração, fazendo dos motivos não reais, nem por isso menos determinante, o móvel das ações, quando estas se transformam em ato. Aos animais não é facultado o conhecimento abstrato, pois, estão fixados necessariamente ao conhecimento intuitivo. Os motivos abstratos podem levar ao erro, isto é, a uma equivocada manifestação do caráter inteligível, ainda que isso em nada altere sua significação íntima.

Com o aparecimento da razão é quase que inteiramente perdida aquela segurança e infabilidade das exteriorizações da Vontade (que no outro extremo, na natureza inorgânica, aparece inclusive como estrita conformidade a leis): o instinto entra por completo no segundo plano. A 
ponderação, que agora deve a tudo subsistir, produz (como exposto no primeiro livro) vacilações e incertezas; o erro se torna possível, obstando em muitos casos a adequada objetivação da Vontade em atos. ${ }^{12}$

Embora o motivo seja a causa necessária que determina o fenômeno da ação, está é decidida em termos metafísicos pela vontade, ou seja, pelo caráter inteligível que, portanto, assegura o conteúdo íntimo das ações, ainda que na diversidade das formas de sua manifestação. Toda ação enquanto fenômeno depende de um motivo, apresentado pelo entendimento que, de modo necessário, põe a vontade em atividade. Porém, em si mesma, a ação não se encontra na dependência dos motivos, pois, provém e é decidida pelo próprio caráter inteligível do indivíduo, que é livre de qualquer determinação temporal, já que é a própria Vontade como coisa-em-si.

Schopenhauer afirmou não ser possível fazer prescrições a vontade/caráter, pois que é livre, estando nela, portanto, a significação ética das condutas. Afirmou ainda que nenhum indivíduo nasce com um zero moral, uma vez que já se nasce com o caráter fixado metafisicamente que, por conseguinte, permanece o mesmo ao longo de toda a vida. Não há liberdade nos atos dos indivíduos quando se faz referência ao mundo dos fenômenos, onde as ações são determinadas pelas relações de causa e efeito. A liberdade da ação só é possível quando se faz referência ao caráter inteligível de cada indivíduo - que é fundamentalmente livre. Os motivos são apenas as causas ocasionais que determinam o fenômeno da ação dos indivíduos, não sendo aquilo que em si mesmo a determina, que é seu caráter inteligível. Assim sendo, as ações dos indivíduos são assumidas sob duas determinações: uma transcendental e outra empírica, havendo uma preponderância da primeira sobre a segunda. No aspecto transcendental, o homem é livre, porque suas ações são realizadas absolutamente conforme seu caráter inteligível.

Sua natureza em-si é o caráter inteligível que está presente igualmente em todos os atos do indivíduo e impresso em todos eles, como o carimbo em mil selos, e que determina o caráter empírico deste fenômeno que se manifesta no tempo e na sucessão dos atos. ${ }^{13}$

O filósofo cunhou também o conceito de caráter adquirido, ao lado dos conceitos de caráter inteligível e de caráter empírico, que foi resultado do seu contato com os escritos de Kant. Este caráter adquirido refere-se ao autoconhecimento do indivíduo que, ao observar a constância de suas ações, pode, pela experiência, reconhecer os limites do seu caráter, alcançando, graças à intelecção, uma economia de forças diante de situações e demandas que, de antemão, fogem as reais possibilidades do seu caráter, constituindo-se como 
o conhecimento mais acabado possível da própria individualidade. Trata-se do saber abstrato, portanto distinto das qualidades invariáveis do nosso caráter empírico, bem como // da medida e direção das nossas faculdades espirituais e corporais, portanto dos pontos fortes e fracos da nossa individualidade. Isso nos coloca na condição de agora guiar, com clareza de consciência e metodicamente, o papel sempre invariável de nossa pessoa, que antes naturalizávamos sem regra, e preencher, segundo a instrução de conceitos fixos, as lacunas provocadas por humores e fraquezas. ${ }^{14}$

O caráter inteligível possui natureza metafísica, enquanto que os caracteres empírico e adquirido são físicos, mediados pelo conhecimento. Este caráter inteligível, da coisa-em-si, ou seja, da Vontade livre, não pode ser educado, alterado e modificado em seu conteúdo íntimo que acompanha toda ação do indivíduo, sendo aquilo que permanece invariável, mesmo diante das diferentes formas de sua exteriorização no caráter empírico. Os demais caracteres, a saber, empírico e adquirido, são oriundos das faculdades do intelecto, sendo passíveis de correção e de aperfeiçoamento, dada a sua condição fenomênica. Trata-se, portanto, da possibilidade de correção e de aperfeiçoamento no conhecimento, porém, não de uma mudança no conteúdo íntimo do caráter, que é imutável e incorrigível.

\section{Caráter Inteligível}

O caráter inteligível tem preponderância, em termos de determinação, sobre os caracteres empírico e adquirido. É metafísico, imutável e incorrigível, tendo por fundamento a vontade, que o imprime no corpo. Este caráter, o único verdadeiro em todo o homem, é absolutamente livre, já que é objetidade não fenomenal da própria Vontade. Vale ressaltar, que essa liberdade é apenas no aspecto transcendental, pois no aspecto empírico não há liberdade para os atos individuais, que estão necessariamente na dependência dos motivos e dos interditos externos que determinam a forma de sua aparição/exteriorização.

O caráter inteligível coincide, portanto, com a Ideia ou, dizendo mais apropriadamente, com o ato originário da Vontade que nela se objetiva. Em verdade, não é apenas o caráter empírico de cada homem, mas também o caráter empírico de cada espécie animal, sim, de cada espécie vegetal e até mesmo de cada força originária da natureza inorgânica que deve ser visto como fenômeno de um caráter inteligível, isto é, de um ato indiviso e extratemporal da Vontade. ${ }^{15}$

Os indivíduos seguem o determinismo do seu caráter inteligível, imutável 
e individual, mesmo que sua exteriorização no caráter empírico seja camuflada por condutas aparentes que se distanciam, por sua vez, de uma exteriorização perfeita do caráter inteligível no caráter empírico, devido a emergência da racionalidade no homem e, por conseguinte, a possibilidade de dissimulação que, em alguns casos, dá-se de modo inconsciente, pois levam os indivíduos ao engano, por se imaginarem capazes de se tornar outra pessoa, quando intentam em não reconhecer aquilo que é peculiar ao seu caráter inteligível, negando o operari sequitur esse ${ }^{16}$ dos escolásticos. "[...] Todas as ações particulares do homem são apenas a exteriorização sempre repetida de seu caráter inteligível (embora possa variar alguma coisa na forma) [...]" ${ }^{17}$ Para Schopenhauer, não é possível ao homem, pelo acesso ao conhecimento, adotar uma nova conduta, pois o caráter é imutável.

Evidentemente, os autores desse dogma conheciam a invariabilidade do homem; sabiam que sua vida, sua conduta, seu caráter empírico, enfim, era apenas a manifestação do seu caráter inteligível, o desenvolvimento de certas tendências determinadas já visíveis na criança, imutáveis; de modo que, desde o nascimento, a conduta de cada um está fixada e permanece, no essencial, idêntica a si mesma até o fim. Concordo com tudo isso. ${ }^{18}$

Por conta da imutabilidade do caráter, somente é possível ao intelecto apresentar a diversidade dos motivos aos indivíduos, quando estes se veem diante do fato de escolher, porém isso não implica na determinação do conteúdo moral, ou seja, do caráter. A escolha é determinada mesmo diante do confronto com a diversidade dos motivos, que podem definir a forma de exteriorização de uma ação, sem contudo tocar em sua significação íntima, que é inacessível, pois os motivos apenas determinam o fenômeno, isto é, a forma de exteriorização do caráter e não o que ele é em si mesmo. "Na esfera do intelecto a decisão entra em cena de modo totalmente empírico, [...] contudo, esta se produziu a partir da índole, do caráter inteligível, da vontade individual [...]." 19 Por conseguinte, cada ação deve ocorrer necessariamente em consonância com as determinações do caráter inteligível, entendido como "um ato extratemporal, indivisível e imutável da vontade [...]." ${ }^{20}$ Assim sendo, não há escolha livre no caráter empírico, pois apenas atua na forma de exteriorização e não naquilo que se exterioriza.

Nesse sentido, quando uma escolha se apresenta, ele não possui dado algum sobre o que a vontade decidirá, pois o caráter inteligível, em virtude do qual diante de motivos dados // só UMA decisão é possível, a qual conseguintemente é necessária, não se apresenta acessível ao conhecimento do intelecto - tão somente o caráter empírico lhe é cognoscivel, de forma sucessiva e por atos isolados. ${ }^{21}$ 
A imutabilidade do caráter torna impossível o ensino da virtude, como pensavam os estoicos, pois, neste caso, há uma eleição da natureza, que incutiu nos indivíduos uma disposição de caráter para as ações genuinamente compassivas, únicas dotadas de valor moral, segundo Schopenhauer. Tendo uma disposição de caráter compassiva ou maldosa, o indivíduo irá exprimir na prática o conteúdo íntimo dessas disposições, sem que qualquer mediação pedagógica possa mudar o âmago para o qual elas se direcionam, sendo apenas possível a mudança da via, porém jamais o alvo.

Ter consciência da imutabilidade do caráter torna-se indispensável, segundo as constatações desse estudo, pois evita o conflito interior, tanto de quem prescreve como de quem deve acatar as normas estabelecidas, ao impor, de modo irrefletido, que o indivíduo se transforme em outra pessoa pela obediência as normas, uma vez que, não há como alterar o imutável que lhe atravessa substancialmente, a saber, o seu caráter inteligível. Tal constatação não invalida a relevância da constituição das normas - tão caras à ordem social, que funciona como um instrumento inibidor da agressividade própria aos indivíduos de disposição de caráter maldosa - mas chama à atenção quanto aos riscos de se alimentar a ilusão da possibilidade de intervenção na natureza do caráter dos indivíduos.

Admitir essa perspectiva, da imutabilidade do caráter, leva à frustração permanente em dois aspectos: 1. daqueles que querem a eficácia, em termos de adesão, das normas instituídas, quando se deparam com a contínua transgressão dos indivíduos, sendo estes, muitas vezes, também transgressores; 2 . daqueles que são obrigados a modificar suas tendências inatas, por conta de uma falha em seu autoconhecimento, vivendo a angústia diária provocada pela inadequação entre os atos realizados e o próprio querer. A autoadmissão do que se é, portanto, levaria a uma significativa redução do otimismo e da frustração de alguns indivíduos frente aos insucessos de suas tentativas, sempre infelizes, de transformação do próprio caráter.

A moral, quando nos é apresentada através da religião ou da filosofia, não pode nos tonar melhores: isto é certo. Mas ela pode nos tornar mais refletidos, porquanto aquilo que, sendo estranho à razão e originando-se da consciência melhor, é dado a razão, por meio da abstração, na forma de máximas, sob as quais devem estar todas as nossas ações ${ }^{22}$.

O caráter inteligível é o que está no âmago das ações dos indivíduos, sendo a condição necessária de sua possibilidade e significação, como é, também, o que há de mais originário neles (o indivíduo), pois é a vontade livre. Em seu caráter inteligível, o indivíduo é pura liberdade, na medida em que se reconhece capaz de exercê-la sem interditos, ainda que só subjetivamente, em função dos impedimentos externos que impõem a forma de sua manifestação, 
tratando-se, pois, de uma autêntica liberdade do querer fenomênico.

\section{Caráter empírico}

O caráter empírico é a exteriorização, no tempo e nos atos dos indivíduos, do caráter inteligível, sendo tão somente um querer fenomênico. $\mathrm{E}$ como querer fenomênico, encontra-se dependente, de modo necessário, da presença dos motivos que determinam a forma de exteriorização do caráter inteligível, ainda que tal determinação não toque sua significação íntima. Dada esta condição, os indivíduos fazem a experiência de um conflito incessante, quando em seus atos, verificam a disparidade entre a forma de manifestação do caráter empírico e o conteúdo íntimo do seu caráter inteligível, sendo este aquilo que se reconhece como peculiar a sua pessoa, quando resultado de um justo autoconhecimento não acometido por problemas de falsa consciência, quase sempre involuntária.

Mas esse adestramento de si mesmo, sempre fará efeito como uma coerção vinda de fora, contra a qual a natureza nunca cessa de resistir, às vezes violando-a inesperadamente. [...] Essa relação do caráter empírico com o inato confirma, pois, uma sentença do imperador Napoleão: Tudo que não é natural é imperfeito [...]. ${ }^{23}$

Schopenhauer apontou para o fato de que os indivíduos não podem conhecer o seu caráter inteligível por inteiro e nem todos os motivos aos quais estão expostos, pois se isso ocorresse, haveria como prever todas as ações de forma integral e com isso ser possível frear sua realização. É justamente o caráter empírico de cada indivíduo que irá lhe oferecer as condições para, ao se observar a constância de suas ações, conhecer o grau de sua maldade ou compaixão no curso do tempo que, por sua vez, leva ao caráter adquirido acerca de si mesmo. Porém, isso só pode ser pressuposto a cada ação efetivada (a posteriori), pois do contrário, os indivíduos poderiam se equivocar acerca de suas próprias qualidades e defeitos.

As ações decorrem do ser, trazendo cada ser a marca da pessoa de quem é: isso pode fazer o caráter parecer misterioso, mas Schopenhauer nos assegura que só o conhecemos, nos outros e em nós mesmos, a partir de suas manifestações empíricas - na verdade, da mesma forma como conhecemos o caráter da cera ou da prata clorada. ${ }^{24}$

Sendo a visibilidade do caráter inteligível no tempo, o caráter empírico, excluindo os casos de falsa consciência involuntária, permite que o indivíduo 
possa conhecer, ainda que por analogia, o seu próprio caráter inteligível na realização de suas ações. As ações realizadas, ainda que encontrem problemas quanto à sua exata manifestação (no que diz respeito à forma), mediante o seu conteúdo moral, podem fornecer dados imprescindíveis para a suposição do caráter inteligível não somente para o indivíduo, mas também para aqueles que estão ao seu entorno. É graças ao caráter empírico, que é manifestação fenomênica do caráter inteligível, que se tornou possível a qualificação das ações dos indivíduos em egoístas, maldosas ou compassivas.

Os intérpretes esqueceram de salientar que, além dessa distinção metafísica (inteligível e empírico), Schopenhauer fornece também uma diferença ética dos caracteres que lhe permitirá falar em uma "disposição" [Stimmung] de caráter egoísta, maldosa e compassiva. ${ }^{25}$

Pelo caráter empírico, pode-se falar em "[...] uma descrição tipológica dessas disposições do caráter para explicar a variabilidade das condutas humanas, ou seja, a maneira frequente porém múltipla de atuação das vontades humanas [...], ${ }^{26}$ já que ele fornece, em termos de ações visíveis, o material para essa descrição tipológica que, ao ser realizada, permite supor a diferença ética dos caracteres, dada a observação dos traços do caráter inteligível em sua exposição no caráter empírico, embora o que é essencial do caráter inteligível não esteja nessas formas, pois que está fora do tempo.

O caráter empírico é absolutamente determinado pelo caráter inteligível, o qual é sem-fundamento, isto é, não está, enquanto coisa-em-si, Vontade, submetido ao princípio de razão (forma do fenômeno). O caráter empírico tem de fornecer num decurso de vida a imagem-cópia do caráter inteligível, e não pode tomar outra direção a não ser aquela que permite a essência deste último. Semelhante determinação estende-se apenas ao essencial, não ao inessencial do decurso de vida que assim aparece. Ao inessencial pertence a determinação detalhada dos eventos e ações, que são o estofo no qual o caráter empírico se mostra; eles são determinados por circunstâncias externas que fornecem os motivos aos quais o caráter reage em conformidade com sua natureza. ${ }^{27}$

Se não houvesse o caráter empírico, o caráter inteligível seria apenas um conteúdo formal, de natureza metafísica, onde não haveria, portanto, nenhuma possibilidade de pressuposição do seu conhecimento. $O$ conhecimento do caráter inteligível não significa conhecê-lo em termos metafísicos, mas reunir, ainda que de modo mínimo e negativo, um conhecimento possível, mediante sua exteriorização nas formas do princípio de razão (espaço e tempo), que possibilita o indivíduo, apesar dos riscos de uma falsa consciência involuntária, conhecer a sua própria pessoa. 


\title{
Caráter adquirido
}

O caráter adquirido é a consciência da soma das ações que são fornecidas pelo caráter empírico, ou seja, é a admissão que os indivíduos fazem, do ponto de vista da consciência, acerca do que se imaginam ser, dada a frequências dessas mesmas ações. Isso acarreta uma incerteza, diante dos problemas relacionados à exteriorização das ações, pois o caráter adquirido pode incorrer em contradições ao levar o indivíduo a se reconhecer como portador de um caráter que se encontra em íntima disparidade com o conteúdo moral do seu caráter inteligível. Essa contradição incute no indivíduo um sentimento de angústia mediante a consciência dessa disparidade, que revela, por conseguinte, um autoconhecimento distorcido.

\begin{abstract}
Este nada mais é senão o conhecimento mais acabado possível da própria individualidade. Trata-se do saber abstrato, portanto distinto das qualidades invariáveis do nosso caráter empírico, bem como // da medida e direção das nossas faculdades espirituais e corporais, portanto dos pontos fortes e fracos da nossa individualidade. Isso nos coloca na condição de agora guiar, com clareza de consciência e metodicamente, o papel sempre invariável de nossa pessoa, que antes naturalizámos sem regra, e preencher, segundo a instrução de conceitos fixos, as lacunas provocadas por humores e fraquezas. ${ }^{28}$
\end{abstract}

Por conseguinte, o caráter adquirido é a consciência de si, que leva os indivíduos a se afirmarem como possuidor de virtude ou defeito, ainda que este último seja o menos eventual. Os caracteres empírico e adquirido só são possíveis mediante o intelecto, em função de sua faculdade de memória e de reflexão, que faz os indivíduos se colocarem a si mesmos como objeto de avaliação e classificação dos limites e das possibilidades do alcance de suas práticas, o que lhes permitem evitar desgastes desnecessários frente às conquistas que não são compatíveis com a disposição do próprio caráter, sejam estas físicas ou psíquicas.

Afetar alguma qualidade, gabar-se dela, é uma confissão de não possuí-la. Uma pessoa pode vangloriar-se de ter coragem, erudição, inteligência, espirituosidade, sucesso junto às mulheres, riqueza, posição social ou qualquer outra coisa e nós podemos concluir que justamente nessa matéria Ihe falta algo. Pois quem de fato possui por inteiro uma qualidade não pensa em expô-la nem em afetá-la, mas a esse respeito permanece bem calmo. ${ }^{29}$

Ter o caráter adquirido pressupõe, portanto, o conhecimento da própria 
individualidade, ou seja, dos limites do próprio caráter. Com a admissão de tal caráter, os indivíduos aprendem pela experiência aquilo que quer e pode fazer, evitando o esgotamento desnecessário de suas forças na obtenção de algo que não se coaduna com as disposições do seu caráter. Pelo caráter adquirido, estes indivíduos aprendem o que se torna possível de ser alcançado, diante das muitas coisas que são desejadas, ao prever o grau de força que the é próprio frente a certas conquistas. Essa postura, resultante do autoconhecimento, evita a virulência da sensação contínua de desejo contrariado a que os indivíduos estão fadados, quando, por desconhecimento dos próprios traços de caráter, se arvoram em certos objetivos que terminam por não lhe trazer nenhuma satisfação.

Pois assim como o peixe só se sente bem na água, o pássaro no ar, a toupeira debaixo da terra, todo homem só se sente bem na sua atmosfera apropriada. Do mesmo modo, por exemplo, o ar da corte não é respirável por todos. Por falta de intelecção suficiente nessa ordem das coisas, muitos fazem os mais diversos e fracassados tipos de tentativas, violam o próprio caráter no particular e ainda têm de se render novamente a ele no todo: aquilo que conseguem tão penosamente contra a própria natureza não lhes dá prazer algum. $\mathrm{O}$ que assim aprendem permanece morto ${ }^{30}$.

Por mais hediondo que possa ser o caráter de um indivíduo, as instituições educativas, que comungam da ideia de melhoria dos indivíduos, não poderão interferir no conteúdo ontológico do caráter, mas tão somente na sua forma de exteriorização, pois o indivíduo jamais poderá se desvencilhar do seu caráter, ainda que passe toda a vida a repudiá-lo. A educação é necessária, porém não suficiente para melhorar os indivíduos, sendo apenas um instrumento eficaz, enquanto instituição fundamentalmente repressiva, pela lembrança diária ao indivíduo dos castigos e das punições que seus atos podem acarretar, fazendo com que eles contenham suas inclinações de caráter mais escusas.

A finalidade da educação, segundo a perspectiva assumida durante o curso da investigação, constitui-se em tarefa nobre, pois a inibição da exteriorização dos traços de um caráter maldoso, que ameaça a vida em sociedade, contribui bastante na redução dos males que assolam as relações humanas. Porém, tal perspectiva não se opõe as políticas educacionais de conscientização dos indivíduos que, dada a forma como são empreendidas, podem conferir aos indivíduos um autoconhecimento do próprio caráter que, por sua vez, auxiliem no entendimento das vantagens e desvantagens acerca do próprio caráter frente às demandas da realidade.

[...] Pela experiência nos tornamos cônscios da inflexibilidade do caráter 
alheio e até então acreditávamos de modo pueril poder através de representações abstratas, pedidos e súplicas, exemplos e nobreza de caráter fazê-lo abandonar seu caminho, mudar seu modo de agir, despedirse de seu modo de pensar, ou até mesmo ampliar suas capacidades; [...]. ${ }^{31}$

Somente por um sensato autoconhecimento do seu caráter é possível ao indivíduo saber "o gênero e a medida de seus poderes e fraquezas, economizando assim muita dor." 32 O processo diário do autoconhecimento poupa-o da árdua tarefa de suportar aquilo que pode contrariar seu próprio caráter, guardando-o da frustração "de tentar aquilo que não o permitirá ser bem-sucedido." ${ }^{33}$ Porém, faz-se preciso ressaltar que o caráter adquirido só pode ser alcançado na vida adulta, em decorrência da extensão do conhecimento acerca da própria pessoa, ou seja, do próprio caráter. $\mathrm{Na}$ juventude, este conhecimento se torna inacessível, já que nesse período, o caráter não se tornou conhecido, pois que pressupõe o tempo como condição de sua possibilidade. Isso, portanto, não excluí a possibilidade de indivíduos adultos com conhecimento adolescente acerca do próprio caráter.

Caso tenhamos investigado onde se encontram nossos pontos fortes e fracos, desenvolveremos, empregaremos, usaremos de todas as maneiras os nossos dons naturais mais destacados e sempre nos direcionaremos para onde são proveitosos e valiosos, evitando por inteiro e com auto abnegação aqueles esforços em relação aos quais temos pouca aptidão natural. $^{34}$

Ao se evitar a postura ignóbil frente ao próprio caráter, o indivíduo tornase menos passível de reunir, no decurso do tempo, uma falsa opinião sobre si mesmo que, portanto, contribui de maneira positiva, assim se julga, dando-lhe a consciência prática dos limites e das possibilidades no que diz respeito às reais disposições do seu próprio caráter.

\section{Conclusão}

Diante de tudo que fora exposto, percebe-se que Schopenhauer, em sua descrição dos tipos de caracteres, permanece voltado à solução apresentada por Kant no quis diz respeito ao problema da coexistência da liberdade com a necessidade. Kant concebe o homem sob dois pontos de vista: 1. como ser natural, por conseguinte submetido ao determinismo; 2. como ser inteligível, por conseguinte livre. Sendo esses pontos de vistas assentados na distinção, deveras conhecida, entre fenômeno e coisa-em-si. Porém, vale ressaltar que apesar da concordância quanto a resolução do impasse entre liberdade e 
necessidade, Schopenhauer e Kant atribuem fundamentos distintos para o caráter inteligível. Enquanto Kant lhe atribuiu a razão por fundamento, Schopenhauer o concebeu como a própria vontade livre.

Sendo o caráter inteligível de cada indivíduo metafísico, imutável, inato e incorrigível, Schopenhauer teria se omitido em falar sobre Educação Moral. Tomá-la como possibilidade, viria a contradizer sua filosofia moral. Assim, a educação moral seria "o ajuste da conduta humana a certas normas de valores ou preceitos morais" 35 , porém, vale ressaltar que, segundo a perspectiva de Schopenhauer, esse ajuste não corresponde a uma mudança de caráter mediante a realização de certas ações. As ações são condicionadas pelas regras externas que apenas interferem na forma de manifestação do caráter inteligível sem, contudo, tocar em seu conteúdo originário.

[...] se o caráter não fosse, como originário, imutável e por isso impenetrável a toda melhoria mediante a correção pelo entendimento; se, antes, como aquela ética superficial o afirma, fosse possível uma melhoria do caráter mediante a moral, e de acordo com isso, "um progresso para o bem", então, se assim muitas instituições religiosas e os esforços moralizantes não tivessem errado o alvo, a metade mais velha da humanidade teria que ser significativamente melhor do que a mais jovem, pelo menos na média. Há porém tão poucos traços disto que, inversamente, esperamos antes algo de bom dos jovens do que dos velhos, que ficaram piores com a experiência. ${ }^{36}$

Após a recepção da tese da imutabilidade do caráter, torna-se possível pela ordem legal - Lei, Polícia, Direito e Estado - a tarefa de desviar o caráter dos indivíduos de suas inclinações perversas, sem conduto poder melhorá-lo, uma vez que a educação é necessária, mas não suficiente.

para uma melhoria efetiva seria exigível que se transformasse toda a forma de sua sensibilidade para os motivos [...]. Isso porém é por certo mais impossível do que transformar chumbo em ouro. Pois seria preciso que, por assim dizer, se virasse pelo avesso o coração no corpo e que se metamorfoseasse seu âmago mais profundo. ${ }^{37}$

Essa ideia de caráter como algo determinado que, por sua vez, levou Schopenhauer a dar uma resposta negativa à possibilidade da educação moral, segundo a perspectiva de Kleverton Bacelar, vem contrariar os hábitos mentais modernos, pois, a Pedagogia e o Direito Penal apostam veementemente na educabilidade e re-educabilidade moral do homem. ${ }^{38}$ No entanto, a experiência quotidiana encarrega-se de mostrar a ingenuidade de tal pretensão.

A educação não pode mudar o caráter dos indivíduos, pois, este já se "encontra fixamente determinado desde o nascimento e no essencial permanece o mesmo até o fim da vida." $39 \mathrm{Na}$ vida, portanto, haverá "o 
desenvolvimento de decididas e imutáveis disposições já reconhecidas na criança." 40 Apenas resta a educação, como algo externo, propor a forma de direção do caráter/vontade, sem que com isso esteja assegurada a mudança de sua verdadeira inclinação.

Por conseguinte, instrução e conhecimento aperfeiçoado, vale dizer, ação do exterior, podem ensiná-la que errou nos meios e assim fazê-la buscar o fim pelo qual se esforçava, de acordo com sua essência íntima, por um caminho inteiramente outro e até mesmo num outro objeto; jamais, entretanto, podem fazer com que realmente queira de maneira diferente do que quis até então, o que permanece inalterável $[\ldots]^{41}$

Desde modo, a educação apenas poderá fornecer situações para que cada indivíduo possa refletir sobre as tendências do seu caráter, porém, essa reflexão em nada poderá ajudar, já que as decisões definitivas acerca da ação de um indivíduo provêm do seu próprio caráter, possibilitando, assim, diante do contentamento ou descontentamento da ação realizada, o conhecimento do que se é. Quanto mais a educação se esforça para manter o indivíduo consciente das consequências de suas ações para consigo mesmo, o conhecimento obtido lhe assegura condições melhores de autoconhecimento, que impede decepções na tentativa de querer se transformar em outra pessoa.

Schopenhauer é um cético com relação à moralidade. Não há como mudar a disposição do caráter. Ele é livre como o é a própria vontade do indivíduo, que em Schopenhauer designam as mesmas coisas, já que o caráter é a forma da vontade objetivada no homem. A um leitor desavisado, tal concepção de caráter parece incitar a certo permissivismo moral, mas, pelo contrário, apenas quis ser uma reflexão sobre os limites e as possibilidades de modificação da natureza humana. A filosofia, o filósofo apenas atribuiu a tarefa de interpretar e explanar o agir humano, sem nunca poder intervir ou modificar o caráter dos indivíduos, sendo impossível conceber uma filosofia prescritiva.

A filosofia, portanto, estaria resumida unicamente a uma exposição abstrata do que é o agir humano, sem qualquer possibilidade de se constituir em uma práxis que, por mediação, viesse a modificar as disposições metafísicas do caráter. O que pode a Ética?, assim perguntou o filósofo no $\S 20$ da obra Os Dois Problemas Fundamentais da Ética, mais especificamente na parte intitulada Sobre o Fundamento da Moral. A resposta dada a sua própria questão é negativa, pois, a Ética nada poderá com relação á mudança de caráter, porém, sem hesitar, o filósofo acredita veementemente na força dos mecanismos de repressão e coerção, utilizados pelas instituições que se definem educativas, pois, somente por meio desses mecanismos é possível conter a virulência das disposições metafísicas do caráter, quando estas se constituem em ameaça para a vida em sociedade. 


\section{REFERÊNCIAS}

CACCIOLA, Maria Lúcia Melo e Oliveira. Schopenhauer e a questão do dogmatismo. São Paulo: UNESP, 1994.

JANAWAY, Christopher. Schopenhauer. Trad. Adail Ubirajara Sobral. São Paulo: Edições Loyola, 2003.

HOZ, V. G. Dicionário de Pedagogia. Barcelona: Editorial Labor, 1970.

PERNIN, Marie José. Schopenhauer: decifrando o enigma do mundo. Tradução de Lucy Magalhães. Rio de Janeiro: Jorge Zahar, 1995.

KANT, Immanuel. Crítica da razão pura. Tradução de Valério Rohden e Udo Baldur Moosburger. $3^{\mathrm{a} e d . ~ S a ̃ o ~ P a u l o: ~ N o v a ~ C u l t u r a l, ~ 1987-88 . ~}$

SANTANA, Kleverton Bacelar. Sobre a IV motivação na Psicologia de Schopenhauer. Associação Nacional de Pós-Graduação em Filosofia (Anais), 2004.

- Schopenhauer e a impossibilidade da educação moral: comentário do capítulo XXVIII dos Paralipomena. Colóquio Internacional sobre Schopenhauer. Pontifícia Universidade Católica do Rio de Janeiro, 2009.

SCHOPENHAUER, Arthur. O mundo como vontade e representação. Tradução: Jair Barboza. São Paulo: UNESP, 2005.

. El mundo como voluntad y representación II (Complementos).

Tradução: Pilar López de Santa Maria. Madrid: Editorial Trotta, 2005.

Aforismos para sabedoria de vida. Tradução: Jair Barboza. São Paulo: Martins Fontes, 2006.

- Sobre o fundamento da moral. Tradução: Maria Lúcia Mello e Oliveira Cacciola. São Paulo: Martins Fontes, 2001.

\footnotetext{
${ }^{1}$ SCHOPENHAUER, Arthur. Sobre o Fundamento da Moral. p. 96.
} 


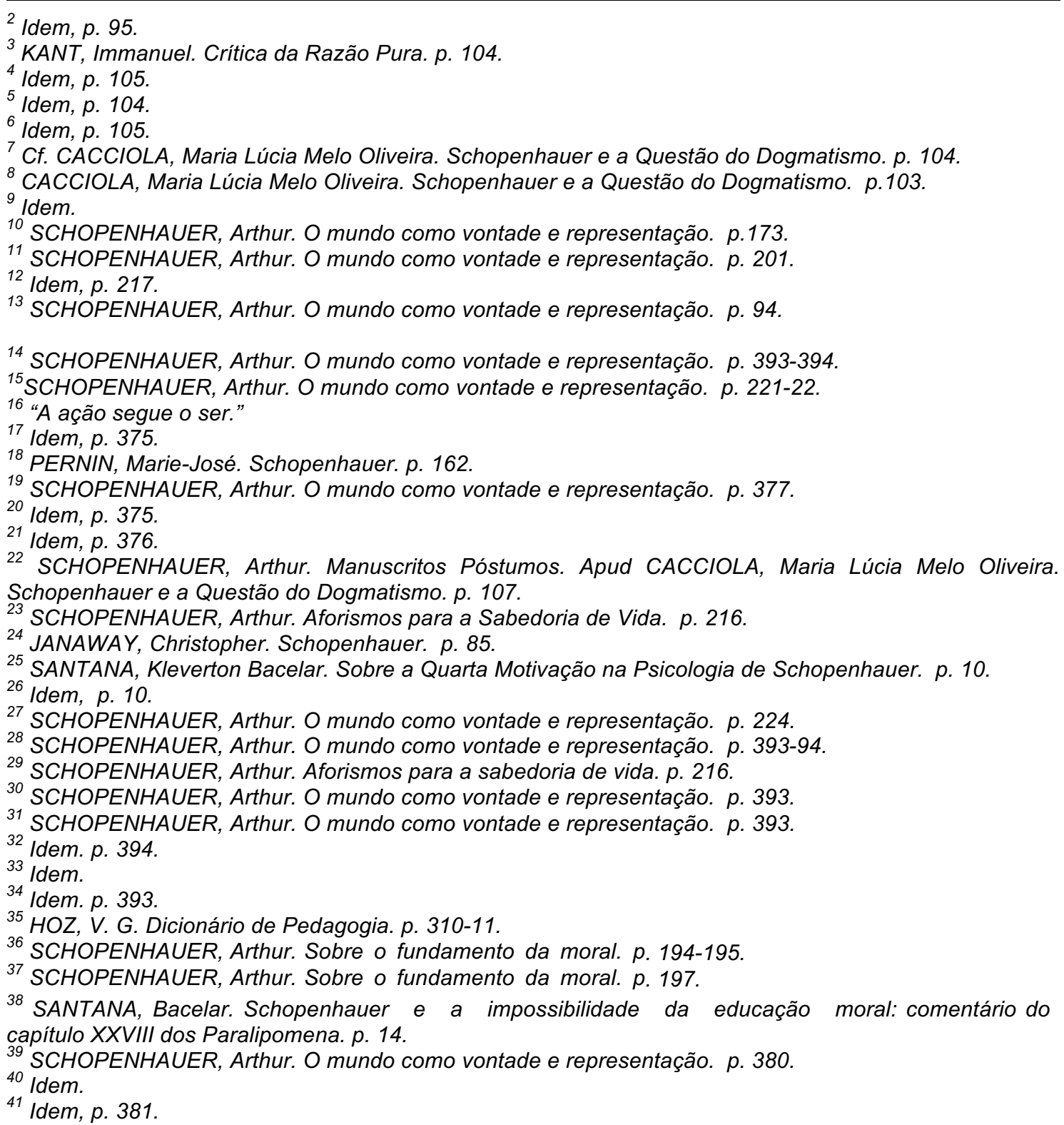

